\title{
Incorporating Graduate-level Internships to Strengthen the STEM Workforce and Trainee Career Prospects
}

\section{$\underline{\text { Neysha Martínez-Orengo }}{ }^{1}$, Mallory R. Smith ${ }^{2}$, D. Thad} Whitaker $^{3}$, Moraima Castro-Faix ${ }^{4}$

${ }^{1}$ Ponce Health Sciences University, Department of Basic Sciences, Ponce, PR

${ }^{2}$ University of Kansas Medical Center, Department of Biochemistry and Molecular Biology, Kansas City, KS

${ }^{3}$ Texas A\&M University, Texas A\&M Institute for Neuroscience, College Station, TX

${ }^{4}$ Rutgers University, Graduate School of Education, New Brunswick, NJ

https://doi.org/10.38126/ISPG190108

Corresponding author: neyshamo@gmail.com

Keywords: STEM Opportunities Act of 2019; professional development; STEM workforce; graduate training; higher education; internships

Executive Summary: The science, technology, engineering, and mathematics (STEM) fields in the United States are currently facing a crisis: graduate programs are not adequately preparing all trainees for the diverse career paths on which they embark. Over recent years, this problem has intensified as the number of Ph.D. holders increased and academic research jobs stagnated or shrunk. Still, most STEM doctoral programs have maintained the singular focus on training students for academic careers at a cost to the individual's career, society, and the economy. Universities and graduate institutions must adapt to meet the increasing demand for STEM laborers in non-academic sectors and provide relevant and robust training to their students. We propose amending the STEM Opportunities Act of 2019 to incentivize institutions to integrate experiential learning and expand training services. Provided diverse career-training, highly-skilled Ph.D. graduates will more efficiently enter and fill the STEM workforce, stimulating the U.S. economy. Addressed to: The Committee on Science, Space, and Technology, United States House of Representatives; and the Senate Committee on Health, Education, Labor, and Pensions.

\section{STEM Workforce Supports U.S. Economic} Growth

STEM fields provide the United States with the technical expertise necessary to tackle complex national and global challenges including, but not limited to, human health, climate change, food production, sustainability, and national security (Mirchandani 2020). It is estimated that the entire STEM industry will constitute thirteen percent of the U.S. workforce in 2027, yet it is already facing 2 million unfilled jobs. This gap is predicted to widen to 4.4 million by 2025. Moreover, STEM fields directly and indirectly support approximately two-thirds of all U.S. jobs and gross domestic product, contributing significantly to recent economic growth (FTI Consulting 2020; Croak 2018; Light 2018; Rothwell 2013). Despite this invaluable contribution, graduate schools are falling short on providing training opportunities that will prepare their students for the diverse STEM career pathways beyond academia. Graduate programs are not a one-size-fits-all plan. However, we hypothesize that providing experiential learning opportunities (e.g., internships, capstones) in a wide range of STEM sectors can better prepare these candidates and bridge the gap between talent and the increasing STEM workforce demand. 
II. Non-academic Careers are no Longer "Alternative Careers"

Professorship continues to be one of the most desired career options within Ph.D. candidates; nevertheless, a very small percentage of these candidates will become an academic appointee (Woolston 2019). Despite the saturated academic job market and growing STEM workforce, most graduate training programs continue to cultivate the mindset that pursuing careers in STEM other than academic careers is a sign of failure (Kruger 2018). Under these competitive market constraints, doctoral graduates face unique challenges, such as opting for extended academic research training, i.e., postdoctoral fellowships, securing jobs with lower education requirements, or exiting traditional STEM careers altogether. Furthermore, Ph.D. recipients have more difficulty entering the STEM workforce than those earning master's degrees, likely because these recipients have increased exposure to job market skills and incur a lower cost to employ (Bell 2012). Data collected from recent doctoral recipients show an increasing number of STEM degree recipients, yet a stagnant number are entering 'traditional' academic careers (Figure 1). Other sectors, particularly in the broadly-defined for-profit industry, continue to absorb the remaining graduate students (Figure 1). Together, these data demonstrate a significant number of STEM graduates ready to enter STEM careers, but they may face a mismatch between degree and job types or abrupt transitions to non-academic careers.

\section{Graduate Trainee Retention is Low Within Minority Group Segments}

The attributes and demographics of STEM trainees/workers can be segmented to identify whether any alarming trends are leading to poor retention in STEM careers. Two populations in particular, women and racial/ethnic minorities, currently see both reduced pursuit of academic training as well as high attrition. Women comprise approximately sixty percent of graduate trainees (Martinez and Christnacht 2021) but only comprise twenty-seven percent of the STEM workforce. This group faces major hurdles that cause approximately fifty-six percent to abandon the industry by mid-career (Hewlett et al. 2008). We find three factors that contribute to this trend: 1) two-thirds

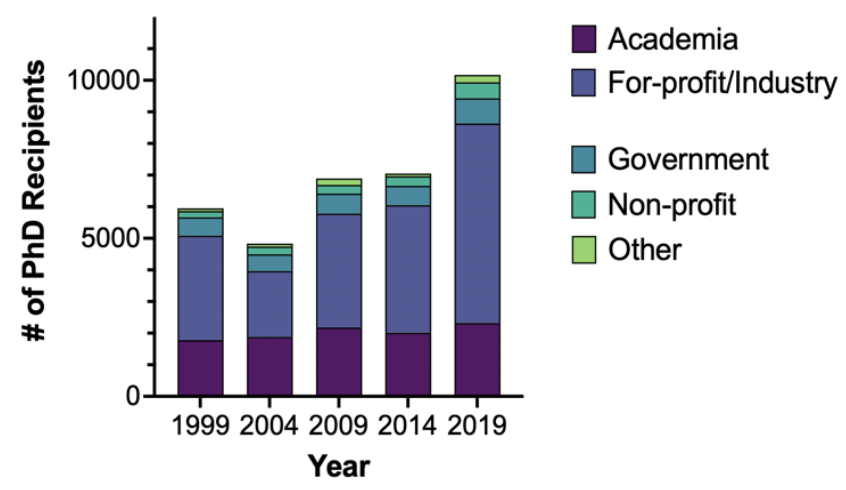

Figure 1: Employment sectors of recent STEM doctoral recipients. Data sourced from Table 46, National Center for Science and Engineering Statistics, National Science Foundation. 2019. Doctorate Recipients from U.S. Universities: 2019. NSF 21-308. Alexandria, VA. Available at https://ncses.nsf.gov/pubs/nsf21308/

feel unsupported in pursuing STEM careers (Emerson 2019); 2) prominent male faculty train ten to forty percent fewer women relative to other faculty (Scheltzer and Smith,2014); 3) and a significant wage gap exists compared to men even when adjusting for training and education (Michelmore and Sassler 2016). Furthermore, women face unique societal barriers, e.g., often being the primary caregiver while trying to achieve work/life balance (Hansen 2020). Studies also indicate that Black and Hispanic populations are underrepresented in STEM careers compared to the total workforce (Black: nine versus eleven percent, respectively; Hispanic: eight versus seventeen percent, respectively) (Kennedy et al. 2021). One reason is that sixty to sixty-four percent of Hispanic/Latinx and Black STEM doctoral students do not complete their degree as compared with fifty-five percent for white students (Sowell et al. 2015). This racial disparity in degree completion may arise due to a combination of program and personal challenges, including insufficient financial support (Kennedy et al. 2021), program requirements (Sowell et al. 2015), a lack of support and mentorship (Miriti 2020), and feelings of isolation that come with being underrepresented in their graduate programs (also faced by international students who are dealing with a new culture and 
language) (Rainey et al. 2018). Obstacles for individuals that intersect between multiple groups, e.g., Black women, are even more severe. While efforts to decrease attrition within women and other minority groups have and are currently being proposed (such as STEM Opportunities Act of 2019 and Women and Minorities in STEM Booster Act of 2019), we investigated other intrinsic areas in graduate programs that could lead to improved career outcomes for these underrepresented groups (Estrada et al. 2016).

\section{Graduate Training Programs Fail to Provide} Adequate Opportunities for Career Development Graduate students feel less prepared for non-academic career paths despite the significantly higher number of non-academic careers as compared to academic careers (Okahana et al. 2019). Still, many graduate programs are deficient in two key non-academic career-development areas: 1) a lack of funding or financial resources for students to explore diverse career paths; 2) a lack of information, training, and mentorship support for trainees pursuing non-academic career paths. Although most graduate programs offer professional development opportunities intended to diversify career exploration by means of seminars and career panels, more substantive programming, e.g. internships, are not prevalent despite having a stronger impact on career readiness. Together, the lack of 1) academic careers, 2) awareness/training for non-academic careers, and 3) supportive culture for non-academic careers all compound and contribute to the alarming forty percent of STEM Ph.Ds. that do not have a lined-up job opportunity prior to graduation (Smith 2021). To counteract this trend, some graduate training institutions recently incorporated additional career development opportunities including early career planning, e.g., updating resumes, (Fuhrmann et al. 2011; Fuhrmann 2016) and a few have even piloted internship programs (NIH 2013; Otto 2016; Empower 2020; UCSF 2020). The former resulted in earlier engagement in career-transition related activities and increased mindfulness of future career prospects as reported by participants. The latter resulted in students gaining additional, transferable skills, regardless of their final career path, and helped them build a professional network beyond academic research. Furthermore, the piloted internship programs demonstrated increased confidence in career decision making which allowed for quicker entrance into non-academic STEM careers while not affecting the time-to-degree (Schnoes et al. 2018; Chatterjee et al. 2019). Although the data are encouraging, robust career-development programs like these are limited to a small number of graduate programs. For instance, there are approximately fifteen Broadening Experiences in Scientific Training (BEST) programs with experiential learning out of 131 research intensive universities. Similar programs must be implemented nationwide to provide career-readiness for all STEM trainees.

\section{Policy Options to Inject More Highly-skilled STEM Trainees into the Workforce}

Below we propose two policies to be taken either in conjunction with one another, or at a minimum individually, to improve graduate-level training, boost student retention and transitions, and ultimately reduce STEM workplace shortages.

i. Policy option 1: Amend the STEM Opportunities Act of 2019, Section 9, to develop and fund experiential learning opportunities for non-academic STEM graduate career development.

Section 9 of this Act, Research and Related Activities to Expand STEM Opportunities, describes several approaches for the recruitment, retention, and advancement of individuals from underrepresented minority groups in academic STEM careers. However, this proposal is limited in its approach to only increase the diversity of academic faculty in STEM fields despite the limited availability of academic faculty jobs. It further neglects to provide support, nor opportunities, for underrepresented minorities and the entire talent pool in pursuing non-academic careers for which most will embark. Therefore, it perpetuates the disconnection between STEM training and the current state of the STEM workforce.

We recommend amending this section to explicitly provide appropriations and infrastructure for the implementation and/or expansion of academic and non-academic career development to include experiential learning opportunities for doctoral 
students in STEM research. Additionally, federal agencies funding graduate-level research should incentivize these programs to promote the incorporation of more substantive, non-academic training opportunities into their curricula.

This amendment formalizes the requirement to provide trainees with experiential learning opportunities by incorporating three recommendations: First, eliminate financial burden by providing assistance to cover stipend and housing during internships and other training experiences. Second, establish partnerships with public and private organizations for internship opportunities in which students can increase market appeal by acquiring technical and non-technical skills. Third, allow the option to expand the length of internships as needed to gain valuable work experience and build professional networks that will increase the likelihood of securing interviews and/or being directly hired by the internship company (deJanasz and Forret 2008). However, one significant barrier is that some institutions do not have the administrative infrastructure or culture to support these programs. These hurdles are addressable, and guidelines are available (True 2018; Hora et al. 2017). Yet, institutional buy-in is a prerequisite that should be incentivized through policy and/or funding-level support.

ii. Policy option 2: Amend the STEM Opportunities Act of 2019, Section 9, to modernize career development coursework in all STEM curricula.

Paid, experiential learning programs may not be a viable option for many institutions, at least in the near-term. Nevertheless, Section 9 of the STEM Opportunities Act of 2019 should be amended to support the incorporation of additional, formal coursework, workshops, and other activities that aim to expand technical and non-technical skills required for a variety of academic and non-academic STEM careers. Examples of focused and structured training to develop diverse career skills include: searching for and understanding job postings, appreciation of career trajectory dynamics, and in-demand skills; skills certificate programs; mentorship programs; and career fairs. These should be accompanied by educational workshops or resources for faculty and administration to keep them aware of the current workforce demand and challenges their students may encounter during their transition from graduate school to the STEM workforce.

The advantages of this option are that graduate programs can more quickly adopt these offers in their programs and that the administrative costs would be relatively minor. This is especially true for institutions currently receiving funding mechanisms for research training which already require a professional development component. These opportunities would provide a substantive advantage over the current structure where non-academic career development is often lacking.

\section{iii. Consequences of inaction}

At the federal level, the United States' STEM industries face a severe shortage of appropriately trained workers (Varas 2016). A significant contributor to this problem is that, traditionally, graduate programs focus on preparing their students for careers in academia despite the fact that the vast majority of graduate degree holders will not obtain a job in an academic setting. If action is not taken to prepare all trainees for diverse future careers within STEM industries and address inefficiencies in retaining underrepresented groups within STEM, the national economy will lag behind, and the ability for the nation to address some of today's most pressing issues will be hampered.

\section{Conclusions}

We recommend that both policy options be enacted together to increase funding and add external pressure on institutions to implement both experiential learning programs and formal curricula. This will facilitate each student's decision to pursue a career in academia or transition outside of academic research in order to better support the United States STEM workforce. Current pilot programs have shown success on a limited, individual institution level, and we hypothesize these can be scaled up to encompass all STEM graduate programs. 


\section{References}

Bell, Nathan E. 2012. "Data sources: Strong employment growth expected for graduate degree recipients." Accessed July 19, 2021. https://cgsnet.org/data-sources-strong-emplo vment-growth-expected-graduate-degree-recip ients-0

Chatterjee, Deepshikha, J. Kevin Ford, Julie Rojewski, and Stephanie W. Watts. 2019. "Exploring the impact of formal internships on biomedical graduate and postgraduate careers: An interview study." CBE-Life Sciences Education 18 (2): 18:ar20,1-13.

doi:10.1187/cbe.18-09-0199

Croak, Mallory. 2018. "The Effects of STEM Education on Economic Growth." Honors Theses. 1705. Accessed July 19, 2021. https://digitalworks.union.edu/cgi/viewconte nt.cgi?article $=1622 \&$ context=theses

de Janasz, Suzanne C., and Monica L. Forret. 2008. "Learning the art of networking: A critical skill for enhancing social capital and career success." Journal of Management Education 32 (5): 629-650. doi:10.1177/1052562907307637

Emerson. 2019. "Emerson Global STEM Survey Shows Growing Interest in STEM Careers but Lack of Encouragement, Especially for Women." Accessed May 25, 2021.

https://www.emerson.com/en-us/news/corp orate/global-stem-survey-shows-growing-inte rest-in-careers-lack-of

Empower. 2020. "Education Model Program on Water-Energy Research: The National Science Foundation Graduate Research Traineeship Program at Syracuse University." Accessed May 25, 2021.

https://empower.syr.edu

Estrada, Mica, Myra Burnett, Andrew G. Campbell, Patricia B. Campbell, Wilfred F. Denetclaw, Carlos G. Gutiérrez, Sylvia Hurtado et al. 2016. "Improving underrepresented minority student persistence in STEM." CBE-Life Sciences Education 15(3): 15:es5,1-10 doi: $10.1187 /$ cbe.16-01-0038

FTI Consulting. 2020. "STEM and the American Workforce." Report 2020: 1-47. https://www.fticonsulting.com/insights/repor ts/stem-american-workforce
Fuhrmann, Cynthia N. 2016. "Enhancing graduate and postdoctoral education to create a sustainable biomedical workforce." Human Gene Therapy 27,(11): 871-879. doi: 10.1089/hum.2016.154

Fuhrmann, Cynthia N., D. G. Halme, P. S. O'sullivan, and B. Lindstaedt. 2011. "Improving graduate education to support a branching career pipeline: Recommendations based on a survey of doctoral students in the basic biomedical sciences." CBE-Life Sciences Education 10(3): 239-249 doi:10.1187/cbe.11-02-0013

Hansen, Diana S. 2020. "Identifying Barriers to Career Progression for Women in Science: Is COVID-19 Creating New Challenges?" Trends in parasitology 36 (10): 799-802. doi:10.1016/i.pt.2020.07.016

Hewlett, Sylvia Ann, Carolyn Buck Luce, Lisa J. Servon, Laura Sherbin, Peggy Shiller, Eytan Sosnovich, and Karen Sumberg. 2008. "The Athena factor: Reversing the brain drain in science, engineering, and technology." Harvard Business Review Research Report 10094: 1-100. https://www.researchgate.net/publication/26 8325574 By RESEARCH REPORT The Athena Factor_Reversing_the_Brain_Drain_in_Science_ Engineering and Technology

Hora, Matthew T., Matthew Wolfgram, and Samantha Thompson. 2017. "What do we know about the impact of internships on student outcomes? Results from a preliminary review of the scholarly and practitioner literatures". Wisconsin Center for Education Research: 1-20 https://ccwt.wceruw.org/wp-content/uploads 2021/02/CCWT-report-Designing-InternshipPrograms.pdf

Kennedy, Brian, Richard Fry, and Cary Funk. 2021. "6 Facts About America's STEM Workforce and Those Training for It." Pew Research Center. Accessed May 25, 2021.

https://www.pewresearch.org/fact-tank/2021 104/14/6-facts-about-americas-stem-workforc e-and-those-training-for-it/

Kruger, Philipp. 2018. "Why It Is Not a 'failure' to Leave Academia." Nature 560: 133-134. doi:10.1038/d41586-018-05838-y 
Light, Nanette. 2018. "Industry Leaders want Education to Focus on STEM to help fill 2.4M expected Job Vacancies". Accessed May, 252021. https://www.govtech.com/education/higher-e d/industry-leaders-want-education-to-focus-o n-stem-to-help-fill-24m-expected-job-vacancie s.html

Martinez, Anthony and Cheridan Christnacht. 2021. "Women Making Gains in STEM Occupations but Still Underrepresented." Accessed May 25, 2021.

https://www.census.gov/library/stories/2021 101/women-making-gains-in-stem-occupation s-but-still-underrepresented.html

Michelmore, Katherine, and Sharon Sassler. 2016. "Explaining the gender wage gap in STEM: does field sex composition matter?" RSF: The Russell Sage Foundation Journal of the Social Sciences 2 (4): 194-215. doi:10.7758/RSF.2016.2.4.07

Mirchandani, Rajesh. 2020. "Five Global Issues to Watch in 2021." Accessed May 25, 2021. https://unfoundation.org/blog/post/five-glob al-issues-to-watch-in-2021/

Miriti, Maria N. 2020. "The elephant in the room: Race and STEM diversity." BioScience 70(3): 237-242. doi:10.1093/biosci/biz167

Moseley, Brandon. 2019. "Roby: 2.4 Million STEM Jobs Went Unfilled Last Year." Accessed May 25, 2021.

https://www.alreporter.com/2019/09/24/rob $\mathrm{y}$-2-4-million-stem-jobs-went-unfilled-last-yea r/

National Institutes of Health (NIH). 2013. "NIH announces awards to strengthen the biomedical research workforce." Accessed May 25, 2021.

https://www.nih.gov/news-events/news-ease s/nih-announces-awards-strengthen-biomedic al-research-workforce

National Science Board (NSB). 2018. "Science \& Engineering Indicators of 2018" Accessed May 25 , 2021.

https://www.nsf.gov/statistics/2018/nsb2018 1/assets/561/tables/at02-21.pdf

National Science Foundation (NSF). 2015. "Women, Minorities, and Persons with Disabilities in Science and Engineering" Accessed May 25, 2021.

https://www.nsf.gov/statistics/2017/nsf1731 0 /digest/occupation/overall.cfm
National Science Foundation (NSF). 2020. "Non-Academic Research Internships for Graduate Students (INTERN) Supplemental Funding Opportunity". Accessed May 25, 2021. https://www.nsf.gov/pubs/2021/nsf21013/n sf21013.jsp

Occupational Employment and Wage Statistics (OES). 2020. "STEM data sets." Accessed May 25, 2021.

https://www.bls.gov/oes/additional.htm

Okahana, Hironao, Enyu Zhou, and Timothy Kinoshita. 2019. " Closing Gaps in our Knowledge of PhD Career Pathways: How Well Did a STEM PhD Train Degree Recipients for Their Careers?" Council of Graduate Schools Research in Brief. Accessed May 25, 2021. https://cgsnet.org/ckfinder/userfiles/files/CG $\underline{\text { S CareerPathways April\%202019 WebFinal.p }}$ $\underline{\mathrm{df}}$

Okahana, Hironao, and Enyu Zhou. 2017. Graduate enrollment and degrees: 2006 to 2016. Council of Graduate Schools. Accessed May 25, 2021. https://cgsnet.org/publication-pdf/4642/CGS GED16 Report Final.pdf

Otto, Simone. 2016. "Fellows get an ELITE introduction to local industry." Environmental Factor. Accessed May 25, 2021. https://factor.niehs.nih.gov/2016/11/sciencehighlights/elite/index.htm

Rainey, Katherine, Melissa Dancy, Roslyn Mickelson, Elizabeth Stearns, and Stephanie Moller. 2018. "Race and gender differences in how sense of belonging influences decisions to major in STEM." International Journal of STEM Education 5 ar10: 1-14. doi:10.1186/s40594-018-0115-6

Rothwell, Jonathan. 2013. "The Hidden STEM Economy." Metropolitan Policy Program at Brookings. Accessed May 25, 2021.

https://www.brookings.edu/research/the-hid den-stem-economy/

Schnoes, Alexandra M., Anne Caliendo, Janice Morand, Teresa Dillinger, Michelle Naffziger-Hirsch, Bruce Moses, Jeffery C. Gibeling et al. 2018. "Internship experiences contribute to confident career decision making for doctoral students in the life sciences." CBE-Life Sciences Education 17 (1): ar16. doi:10.1187/cbe.17-08-0164

Sheltzer, Jason M., and Joan C. Smith. 2014. "Elite male faculty in the life sciences employ fewer 
women." Proceedings of the National Academy of Sciences 111 (28): 10107-10112. doi.10.1073/pnas.1403334111.

Sowell, R., Jeff Allum,and Hironao Okahana. 2015. "Doctoral initiative on minority attrition and completion." Washington, DC: Council of Graduate Schools. Accessed May 25, 2021. https://cgsnet.org/ckfinder/userfiles/files/Do ctoral Initiative on Minority Attrition and Co mpletion 2015.pdf

Smith, Christopher T. 2021. "Ph.D. recipients' employment trends: insights from national science foundation data." Accessed May 25, 2021.

https://www.christophertsmith.com/reflectio ns/phd-recipients-employment-trends-insight s-from-national-science-foundation-data

STEM Opportunities Act of 2019. H.R. $\left.2528\left(116^{\text {th }}\right)\right)$. Accessed, May 25, 2021. https://www.govtrack.us/congress/bills/116/ hr2528/summary

The National Academies of Sciences, Engineering, and Medicine (National Academies). 2018. Graduate STEM Education for the 21st Century. Washington, DC: The National Academies Press. doi:/10.17226/25038
True, Michael. 2018. "Starting and maintaining a quality internship program." Accessed May 25, 2021.

https://www.internqube.com/uploads/4/8/0/ 7/4807298/starting an internship program-9 th edition.pdf

UC Irvine GPS-STEM. 2014-2019 Graduate Professional Success for PhD students and Postdocs in Science, Technology, Engineering, and Mathematics" Accessed May 25, 2021

https://gps.bio.uci.edu

UCSF 2020. Graduate Student Internships for Career Exploration Program. Accessed May 25, 2021. https://career.ucsf.edu/phds/career-explorati on/gsice/info-students

Varas, Jacqueline. 2016. "The Native-Born STEM Shortage." Accessed July 19, 2021.

https://www.americanactionforum.org/wp-co ntent/uploads/2016/04/The-Native-Born-STE M-Shortage.pdf

Woolston, Chris. 2019. "PhDs: The Tortuous Truth." Nature 575: 403-406. doi:10.1038/d41586-019-03459-7

Neysha Martinez-Orengo is currently a postdoctoral fellow studying the validation of candidate imaging biomarkers to better understand the pathophysiology of infectious diseases and improve non-invasive diagnostic techniques. She holds a Ph.D. in Biomedical Sciences from the Ponce Health Sciences University in Puerto Rico. Neysha is an active member of the Puerto Rico-Science Policy Action Network (PR-SPAN), a STEAM advocate, mentor, and leader in STEM education and outreach.

Mallory R. Smith is currently a postdoctoral fellow in the field of DNA repair. She holds a Ph.D. in Biochemistry and Molecular Biology from the University of Kansas Medical Center. Her research focuses on how DNA is replicated and repaired after being damaged by UV rays, pollutants, and other environmental exposures. Mallory is an active science policy advocate, a STEM non-profit co-founder, and a former organizer for a state science policy program.

D. Thad Whitaker is a scientific program manager leading teams to understand healthy aging and the alterations that lead to neurological disorders. He holds a Ph.D. in neuroscience from Texas A\&M University. He is active in his communities including a local Washington, D.C. Advisory Neighborhood Commission, various community service opportunities, and career development groups.

Moraima Castro-Faix holds a Ph.D. in the learning sciences from Rutgers University. Her research focuses on studying and developing curricula in the sciences at the middle school and high school level. She is involved in a project with EuroScitizen, which aims to study children's understanding of natural selection, and in which she is translating to Spanish the natural selection book How Piloses Evolved Their Noses. She recently started a scientific program manager position and is part of a team that supports a scholarship for low-income students. 


\section{Acknowledgements}

The authors want to thank the Science Policy Discussion Group in Bethesda, Maryland, for connecting the authors and providing science policy-related exposure.

\section{Disclaimers}

Authors declare no conflict of interest, and their views do not necessarily represent those of their affiliations. 